\title{
Influence of Fluorine-Containing Monomer Content on the Hydrophobic and Transparent Properties of Nanohybrid Silica Polyacrylate Coating Materials
}

\author{
Chih-Ming Huang ${ }^{1}$, Her-Yung Wang ${ }^{2}$, Sing-Yuan Fang ${ }^{1}$ and Wein-Duo Yang ${ }^{1, *}$ \\ 1 Department of Chemical and Materials Engineering, National Kaohsiung University of Science \\ and Technology, Kaohsiung 807, Taiwan; color.jackhuang@gmail.com (C.-M.H.); v27946@gmail.com (S.-Y.F.) \\ 2 Department of Civil Engineering, National Kaohsiung University of Science and Technology, \\ Kaohsiung 807, Taiwan; wangho@nkust.edu.tw \\ * Correspondence: ywd@nkust.edu.tw; Tel.: +886-7-3814526 (ext. 15116)
}

check for updates

Citation: Huang, C.-M.; Wang, H.-Y.; Fang, S.-Y.; Yang, W.-D. Influence of Fluorine-Containing Monomer Content on the Hydrophobic and Transparent Properties of Nanohybrid Silica Polyacrylate Coating Materials. Materials 2021, 14, 4261. https://doi.org/10.3390/ ma14154261

Academic Editor: Anna Kowalewska

Received: 11 July 2021

Accepted: 27 July 2021

Published: 30 July 2021

Publisher's Note: MDPI stays neutral with regard to jurisdictional claims in published maps and institutional affiliations.

Copyright: (c) 2021 by the authors. Licensee MDPI, Basel, Switzerland. This article is an open access article distributed under the terms and conditions of the Creative Commons Attribution (CC BY) license (https:/ / creativecommons.org/licenses/by/ $4.0 /)$.

\begin{abstract}
Nanosilica-modified, fluorine-containing polyacrylate hybrid coating materials, consisting of dodecafluoroheptyl methacrylate (DFMA), methyl methacrylate (MMA), 2-ethyl hexyl acrylate (2-EHA), 3-(trimethoxysilyl) propyl methacrylate (KH-570), and tetraethylorthosilicate (TEOS), are synthesized successfully by free radical polymerization and the sol-gel process. It is revealed that the content of the fluorine-containing polyacrylate hybrid coating materials from DFMA monomers significantly improves the properties of the films. The polyacrylate coating film prepared with a weight ratio of DFMA/MMA at 1:5 exhibits the largest water contact angle of $105.4^{\circ}$, which demonstrates that DFMA can effectively improve the hydrophobicity of the coating film. Moreover, the silicon coupling agent (KH-570) is used to graft silica with acrylate. Spherical in shape, the surface morphology of the nanohybrid film exhibits a core-shell structure, which increases the surface roughness and enhances the hydrophobic properties. The as-prepared fluorine-containing nanohybrid silica polyacrylate film possesses a high transmittance of $89-97 \%$ in the visible light region, indicating its potential as a very attractive solution in many practical areas.
\end{abstract}

Keywords: fluorine-containing; polyacrylate; nanohybrid; hydrophobic properties; visible light

\section{Introduction}

When observing the self-cleaning lotus in nature, the phenomenon of hydrophobicity/ super-hydrophobicity is revealed [1]. The definition of hydrophobicity is that the water contact angle (WCA, $\theta) \theta>90^{\circ}$ of the surface is hydrophobic, and the WCA of the surface $\theta<90^{\circ}$ is hydrophilic [2]. When the surface possesses a WCA $\theta>150^{\circ}$ and a sliding angle (SA) less than $10^{\circ}$, it is called a superhydrophobic surface [3]. The most important factors that affect the hydrophobic properties of the surface are increases in the surface roughness and decreases in the surface energy [4-6]. Thus, the methods applied for manufacturing a hydrophobic surface are etching [7], lithography [8,9], chemical vapor deposition [10], chemical and electrochemical deposition [11,12], anodizing [13,14], plasma treatment [15-17], sandblasting [18], phase separation [19], the sol-gel process [20,21], and layer-by-layer assembly [22,23], among others. However, most of the above methods require multiple steps to complete, or require expensive equipment; they are not economical in practice for industrial applications.

Polyacrylate resin has been characterized by high transparency [24], excellent adhesion [25], diverse monomer sources [26], and high mechanical strength [27], and is the most attractive polymer. However, owing to its insufficient thermal stability, weather resistance, and anti-corrosion properties, it is limited in its practical applications [28].

$\mathrm{SiO}_{2}$ possesses a unique structure and excellent physical-chemical properties, and is widely used to enhance the physical and chemical properties of polymer materials [29]. 
Many silanol groups on the surface of $\mathrm{SiO}_{2}$ not only exhibit good wettability, but also interact with the interface of the mixed resin.

In order to improve the above-mentioned shortcomings of polyacrylate resins, $\mathrm{SiO}_{2}$ nanoparticles with "high surface energy and high specific surface area" are often mixed with the resin, but $\mathrm{SiO}_{2}$ is prone to agglomeration, which leads to phase separation in the organic-inorganic composite. Therefore, the combination of functionalized $\mathrm{SiO}_{2}$ nanoparticles and polyacrylate is an important route to enhance the dispersion and compatibility of the material [30-32].

Recently, a few articles have reported the use of monomer-containing fluorine for applications in modifying the structure of acrylate [33,34]. The modified fluorine-based acrylate resin has a low surface energy on the surface of the coating film, as a result of improvements to the hydrophobicity and thermal stability [35]. In addition, in the synthesis of organic-inorganic composite materials, the surface roughness, water contact angle (WCA), and weather resistance of the composite coating film can be also enhanced [36]. Generally, 3-(trimethoxysilyl) propyl methacrylate (KH-570) or 3-(triethoxysilyl) propyl methacrylate (MPS) is commonly used as a silicon coupling agent for the grafting bridge of organic-inorganic composite materials [37,38]. Tetraethylorthosilicate (TEOS) is utilized as the precursor of the inorganic structure $\left(\mathrm{SiO}_{2}\right)$ through the sol-gel route to graft with the silicon coupling agent (KH-570). After grafting, organic-inorganic cross-linking is achieved, so as to increase the mechanical properties and adhesion of the coating film [39,40]. Increasing the surface roughness can improve the hydrophobic properties of the coating film, but it can also cause light scattering and decrease the transparency property in the visible light [41].

In 2019, a fluorinated/silanized polyacrylate amphiphilic polymer was reported by Zhu et al. [42]. It has been revealed that, by changing the content of 2-perfluorooctylethyl methacrylate (FMA), the surface wettability and protein adsorption performance of the as-prepared polyacrylate film can be significantly regulated. Yu et al. [43] reported a nano$\mathrm{SiO}_{2}$ / fluorinated polyacrylate polyurethane coating film showing both good hydrophobicity and good anti-aging properties. Both the chemical resistance and the mechanical properties of the composite coating were improved by the synergistic effect of the fluorine segments cross-linked in the polymer and nano- $\mathrm{SiO}_{2}$ particles. Moreover, the synthesis of cellulose nanocrystal-armored fluorinated polyacrylate latexes via Pickering emulsion polymerization was reported by $\mathrm{Li}$ et al. [44]. It was shown that the water-oil repellent and mechanical properties of the film could be improved as the content of the used Pickering stabilizer increased. The thermal analysis also exhibited an enhancement of the thermal properties of latex film upon increasing the stabilized content.

Wang et al. [45] published the study of a waterborne polyurethane prepolymer modified with styrene, butyl acrylate, glycidyl methacrylate, and dodecafluoroheptyl methacrylate through a soap-free emulsion polymerization method to obtain the crosslinked, fluorinated acrylate-modified waterborne polyurethane coating, which possessed the characteristics of an external hydrophobic surface constructed by long fluorinated side-chains and an internal double cross-linking system. The preparation of an amphiphilic Janus $\mathrm{SiO}_{2}$ / fluorinated polyacrylate latex film and its application as a hydrophobic fabric agent was reported by Lyu et al. [46]. The water contact angle of the as-prepared fabric increased from $21.4^{\circ}$ to $140.2^{\circ}$, demonstrating a great improvement in hydrophobicity and enhancing the water resistance of the latex film.

Additionally, Shao et al. improved the mechanical properties of fluorine-containing acrylic copolymers obtained by mixing emulsifiers by a semi-continuous seeded emulsion polymerization method [47]. Although the eco-friendly and biodegradable emulsifiers were used to reduce environmental pollution, the hydrophobic effect and conversion rate of the copolymer decreased. To the best of our knowledge, there are a few reports that have studied polyacrylate resin as prepared by fluorine-containing acrylate monomer in order to improve its hydrophobic and anti-corrosion properties. However, there are few studies that focus on the influence of the fluorine content on the hydrophobicity and transparent 
properties in the visible region of the polyacrylate- $\mathrm{SiO}_{2}$ material. In order to adapt to the application of polyacrylate with a high light transmittance in an outdoor environment, this issue is important.

In this study, dodecafluoroheptyl methacrylate (DFMA), methyl methacrylate (MMA), and 2-ethyl hexyl acrylate (2-EHA) were utilized as the monomers, and (3-(trimethoxysilyl) propyl methacrylate, $\mathrm{KH}-570$ ) was used as the silicon coupling agent to synthesize acrylate resin. Then, tetraethylorthosilicate (TEOS) was added by the sol-gel route in order to prepare nanohybrid silica polyacrylate coating materials. By changing the weight ratios of MMA/DFMA, high hydrophobicity and a high light transparency in the polyacrylate films were obtained. The influence of the hydrophobicity, surface roughness, thermal properties, and light transmittance of the coating film surface by the various weight ratios of MMA/DFMA was investigated. The as-prepared polyacrylate- $\mathrm{SiO}_{2}$ nanohybrid material can be applied to the coating of $3 \mathrm{C}$ electronic products, vehicles, and construction industries.

\section{Experimental}

2.1. Materials

Analytical-grade chemicals were used as received, without any further purification. Dodecafluoroheptyl methacrylate (97.0\% purity, Tokyo Chemical, Tokyo, Japan), methyl methacrylate (MMA, 99.0\% purity, Alfa Aesar, Haverhill, MA, USA), 2-ethylhexyl acrylate (2-EHA, 98.0\% purity, Sigma-Aldrich, Saint louis, MO, USA), tetrahydrofuran (THF, 99.8\% purity, Mallinckrodt Chemical, Staines-upon-Thames, England), azobisisbutyronitrile (AIBN, 99.0\%, Aencore, Whitehorse, Australia), tetraethylorthosilicate (TEOS, 98.0\% purity, Sigma-Aldrich,), 3-(trimethoxysilyl) propyl methacrylate (KH-570, 98.0\% purity, Sigma-Aldrich,), and hydrochloric acid ( $\mathrm{HCl}, 37.0 \%$ purity, Aencore) were used for the preparation of the nanohybrid silica polyacrylate coating material.

\subsection{Preparation of Organic-Inorganic Grafting Silica Polyacrylate Material}

First, MMA, DFMA, and 2-EHA were used as the monomers and KH-570 was used as the silicon coupling agent; the starting materials were weighed by the designed amounts and mixed well with $40 \mathrm{~g}$ THF solvent, which was placed in a $250 \mathrm{~mL}$ round bottom flask equipped with a reflux condenser. Then, the flask placed in an oil bath was heated up to $70{ }^{\circ} \mathrm{C}$ and kept at this temperature under a nitrogen atmosphere at a stirring speed of $200 \mathrm{rpm}$. The initiator, $0.02 \mathrm{~g}$ of AIBN, was added to the previously prepared mixed solution, and polymerization was carried out for $5 \mathrm{~h}$ at a constant temperature of $70^{\circ} \mathrm{C}$. After the polymerization reaction was completed, the product was cooled to room temperature.

An amount of $1.0 \mathrm{~g}$ of TEOS was taken and placed in a flask, and then mixed with $\mathrm{HCl}$ aqueous solution ( $\mathrm{pH}$ approximate at 1 ) used as a catalyst to progress the hydrolysis and polycondensation for obtaining a Si-sol by the sol-gel route, in advance.

Finally, the as-obtained Si-sol was dissolved in $5 \mathrm{~g}$ of THF and dropped into the acrylicbased copolymer by peristaltic pump at a rate of $2 \mathrm{~mL} / \mathrm{min}$, and stirred continuously for $16 \mathrm{~h}$ for the grafting for the reaction of $\mathrm{KH}-570$ contained in reaction of polyacrylate and $\mathrm{SiO}_{2}$ to obtain an organic-inorganic silica nanohybrid polyacrylate material. The recipes of the starting materials for the preparation of the nanohybrid silica polyacrylate coating material are shown in Table 1. In this preparation, the weight ratio of DFMA/MMA is taken as the primary variable. In order to keep the weight of the as-prepared polyacrylate fixed, the ratio of each component monomer was designed to change the weight of DFMA and MMA monomers at the same time, but the total weight of DFMA and MMA remained unchanged. In addition, changing both DFMA and MMA at the same time, it is easier to maintain the original stoichiometry of the composition of each monomer in the prepared polymer, avoiding excessive composition deviation of the as-prepared polyacrylate. 
Table 1. The recipes of starting materials for the preparation of the nanohybrid silica polyacrylate coating materials.

\begin{tabular}{|c|c|c|c|c|c|c|c|c|c|c|}
\hline \multicolumn{8}{|c|}{ First Stage (Free Radical Polymerization) } & \multicolumn{3}{|c|}{ Second Stage (Sol-Gel Route) } \\
\hline $\begin{array}{l}\text { DFMA } \\
\text { (g) }\end{array}$ & $\begin{array}{c}\text { MMA } \\
\text { (g) }\end{array}$ & $\begin{array}{c}\text { DFMA/MMA } \\
\text { (Weight Ratio) }\end{array}$ & $\begin{array}{l}\text { DFMA/MMA } \\
\text { (Molar Ratio) }\end{array}$ & $\begin{array}{c}\text { 2-EHA } \\
\text { (g) }\end{array}$ & $\begin{array}{c}\text { KH-570 } \\
\text { (g) }\end{array}$ & $\begin{array}{c}\text { THF } \\
(\mathrm{g})\end{array}$ & $\begin{array}{c}\text { AIBN } \\
(\mathrm{g})\end{array}$ & $\begin{array}{c}\text { TEOS } \\
(\mathrm{g})\end{array}$ & $\begin{array}{l}\mathrm{HCl}_{(\mathrm{aq})} \\
(\mathrm{g})\end{array}$ & $\begin{array}{c}\text { THF } \\
\text { (g) }\end{array}$ \\
\hline 0 & 9.0 & $0 / 9$ & - & 1.0 & 0.05 & 40 & 0.02 & 1.0 & 1.5 & 5.0 \\
\hline 0.5 & 8.5 & $1 / 17$ & $1 / 68$ & 1.0 & 0.05 & 40 & 0.02 & 1.0 & 1.5 & 5.0 \\
\hline 1.0 & 8.0 & $1 / 8$ & $1 / 32$ & 1.0 & 0.05 & 40 & 0.02 & 1.0 & 1.5 & 5.0 \\
\hline 1.5 & 7.5 & $1 / 5$ & $1 / 20$ & 1.0 & 0.05 & 40 & 0.02 & 1.0 & 1.5 & 5.0 \\
\hline 2.0 & 7.0 & $2 / 7$ & $1 / 14$ & 1.0 & 0.05 & 40 & 0.02 & 1.0 & 1.5 & 5.0 \\
\hline
\end{tabular}

\subsection{Preparation of the Silica-Polyacrylate Coating Film}

A doctor blade was used to prepare a coating film for the as-obtained silica-polyacrylate resin. The resin was coated and heat-cured at $75^{\circ} \mathrm{C}$ for $2 \mathrm{~h}$ on a $10 \mathrm{~cm} \times 10 \mathrm{~cm}$ copper substrate to remove water and residual solvents. Then, a dried silica nanohybrid polyacrylate coating film with a thickness of approximately $0.5 \mathrm{~mm}$ was obtained.

\subsection{Characterization}

The organic functional groups of the as-prepared nanohybrid silica polyacrylate materials were characterized by Fourier transform infrared spectroscopy (FTIR; BIO-RAD, FIS-165, Hercules, America). Differential scanning calorimetry (DSC, TA Instruments MDS2920, Milford, CT, USA) and a thermogravimetric analyzer/differential thermal analyzer (TGA/DTA, TA Instruments Q600, Milford, CT, USA) were utilized to reveal the thermal stability of the obtained materials.

The surface structure and morphology of the as-prepared polyacrylate- $\mathrm{SiO}_{2}$ films were analyzed by field emission scanning electron microscopy (FESEM, JEOL JSM-7401F, Tokyo, Japan) and transmission electronic microscopy (TEM, JEOL, JEM-3010). For TEM characterization, the as-prepared organic-inorganic grafting acrylic-based resin was diluted by THF solvent to obtain a solid content approximate $1 \mathrm{wt} . \%$ of diluted acrylic-based resin. Then, the diluted resin was dropped on a 400 mesh carbon-plated copper grid and allowed to dry, and a film coated on the copper grid was obtained for TEM analysis. Moreover, the surface roughness of the material was analyzed by atomic force microscopy (BASO-AFM, Guangzhou, China).

The contact angle is defined as the angle between the solid surface and a tangent to the drop-surface. The water contact angles of the as-prepared nanohybrid Si-polyacrylate films were determined using a contact angle goniometer (NBSI, OSA60, Ningbo, China). Ultraviolet-visible-near-infrared DRS spectroscopy (UV-vis-NIR) (JASCO, V-670, Tokyo, Japan) was utilized to characterize the transparent property of the as prepared coating films in the UV-visible light region.

\section{Results and Discussion}

\subsection{Preparation of Nanohybrid Silica Polyacrylate Coating Materials}

MMA, DFMA, and 2-EHA were used as the monomers and KH-570 was used as the silicon coupling agent, and the acrylic-based copolymer was prepared in THF solvent by a free radical polymerization. Figure 1 indicates the copolymerization reactions of the organic-inorganic nanohybrid silica polyacrylate materials. The schematic of the preparation of acrylic-based copolymer is shown in Figure 1a. 
(a)
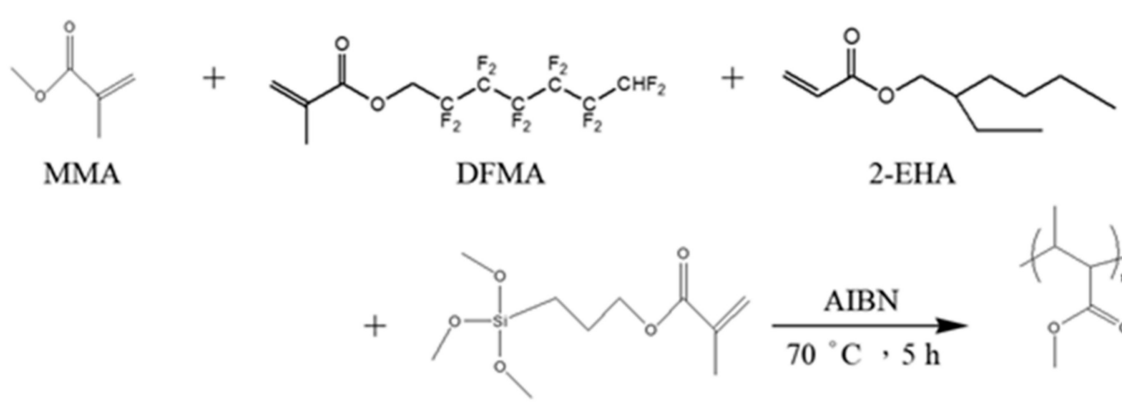

KH570

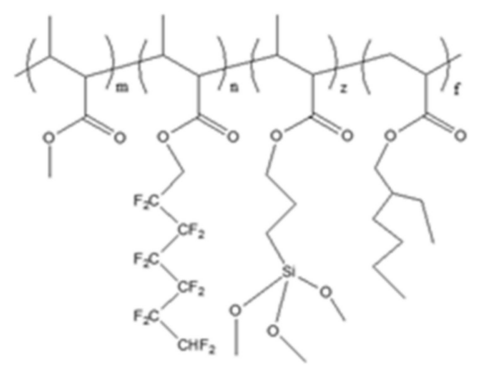

(b)
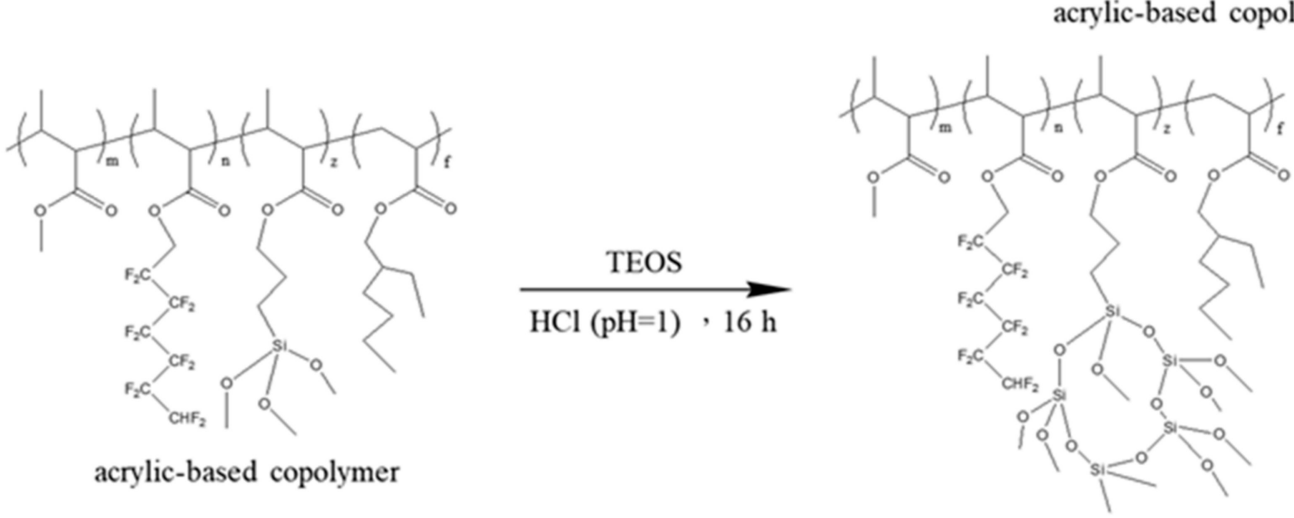

Organic-inorganic grafting acrylic-based material

Figure 1. Copolymerization reactions of the organic-inorganic nanohybrid silica polyacrylate materials: (a) the schematic of the preparation of acrylic-based copolymer, (b) the schematic of organic-inorganic grafting acrylate-SiO $\mathrm{Sesin}_{2}$.

During the preparation process, THF was used as the solvent. THF solvent can uniformly dissolve MMA, DFMA, 2-EHA, and KH570 monomers, allowing to obtain a uniform solution. Therefore, the acrylic-based copolymer (resin) obtained has excellent fluidity. Observing the prepared copolymer, it is transparent, colorless, and has good fluidity. The fluorinated polyacrylate copolymer obtained at this stage has disordered molecular chains. This diluted resin is very beneficial to the preparation of the next stage of organic-inorganic grafting acrylic-based material.

TEOS undergoes hydrolysis and condensation reactions to obtain silica-sol from the sol-gel route. The $\mathrm{pH}$ of the reaction is an important variable. In this study, under acidic condition ( $\mathrm{pH}$ at approximately 1), the hydrolysis and condensation are slow, and the prepared silica-sol is transparent, which is favorable to the grafting reaction of organicinorganic hybrids. Nagarale et al. [48] pointed out that, in the sol-gel reaction of TEOS, irregular linear transparent sols are easily formed under acid catalysts, and uniform white large granular silica precipitates are formed under alkaline catalysts. The schematic of the organic-inorganic grafting acrylate- $\mathrm{SiO}_{2}$ resin is shown in Figure $1 \mathrm{~b}$. When the silica sol is grafted with the fluorinated acrylate copolymer, the $\mathrm{Si}-\mathrm{OH}$ on the silica-sol will be covalently bonded with the silicon coupling agent (KH-570) contained in the as-prepared copolymer to obtain an organic-inorganic grafting acrylic-based resin. The resin prepared is almost colorless and transparent.

After drying at $75{ }^{\circ} \mathrm{C}$ for $2 \mathrm{~h}$, the THF solvent and residual water were removed, and the film thickness was about $0.5 \mathrm{~mm}$. It is not necessary to add a curing agent for the preparation of an organic-inorganic grafting acrylate- $\mathrm{SiO}_{2}$ coating film, which can be obtained by heat treatment only. During the drying process, there is not a violent 
exothermal reaction, and the adhesion between the coating film and the copper substrate is fine.

In the preparation of nanohybrid silica polyacrylate coating materials, it is revealed that, the higher the weight ratios of DFMA/MMA, the slower the evaporation of THF solvent and water, and the slower the film formation. This is because, in the process of heating and drying, the hydrophobic segments of the copolymer will move to the surface of the coating film, and the hydrophilic segments will be below the surface. THF and water are miscible and the $\mathrm{Si}-\mathrm{OH}$ produced by the sol-gel reaction is hydrophilic; therefore, the THF solvent and water under the coating film evaporate slowly, meaning that the film formation will be slower [49].

\subsection{Physical Properties of the As-Prepared Nanohybrid Silica Polyacrylate Material}

Figure 2 shows the FTIR spectrum analysis of the prepared $\mathrm{SiO}_{2}$-polyacrylate material. The figure shows that the absorption peak at around $1729 \mathrm{~cm}^{-1}$ is attributed to the stretching vibration of the characteristic peak of $\mathrm{C}=\mathrm{O}$ [50]. The characteristic bands of $-\mathrm{CH}_{2}$ are present at $1452 \mathrm{~cm}^{-1}$ and $2996 \mathrm{~cm}^{-1}$ [50]. The C-O-C asymmetric characteristic peak in MMA, DFMA, and 2-EHA is identified at the peak of $1250 \mathrm{~cm}^{-1}$. Moreover, the characteristic band at $658 \mathrm{~cm}^{-1}$ is assigned to be the characteristic of $-\mathrm{CF}_{2}$ [51]. When the DFMA/MMA weight ratio increases, the absorption peaks at $1150 \mathrm{~cm}^{-1}$ and $1236 \mathrm{~cm}^{-1}$ increase. The above two peaks are the overlap of C-O-C absorption and the absorption of the stretching vibration of C-F from DFMA $[52,53]$.

The sol-gel method was used to graft $\mathrm{SiO}_{2}$ on the acrylate copolymer, and it was observed that the acrylic-based film possesses absorption bands at $803 \mathrm{~cm}^{-1}$ and $1064 \mathrm{~cm}^{-1}$, which are assigned to the $\mathrm{Si}-\mathrm{O}-\mathrm{Si}$ asymmetric characteristic peak and $\mathrm{Si}-\mathrm{O}$ absorption characteristic peak in $\mathrm{SiO}_{2}$, respectively [54]. In addition, the small amount of the silicon coupling agent $(\mathrm{KH}-570)$ utilized in the sample preparation and the $\mathrm{C}=\mathrm{O}$ group also existed in MMA, DFMA, and 2-EHA; therefore, it is impossible to clearly identify the characteristics of KH-570 from FTIR analysis [34]. Figure $2 b$ is a partial enlargement of Figure 2a, and a broad characteristic band is observed at approximately $3315 \mathrm{~cm}^{-1}$. This may be attributed to the stretching vibration band of the -OH group, which did not undergo a condensation reaction with $\mathrm{KH}-570$ after the hydrolysis of TEOS during the sol-gel process.

(a)

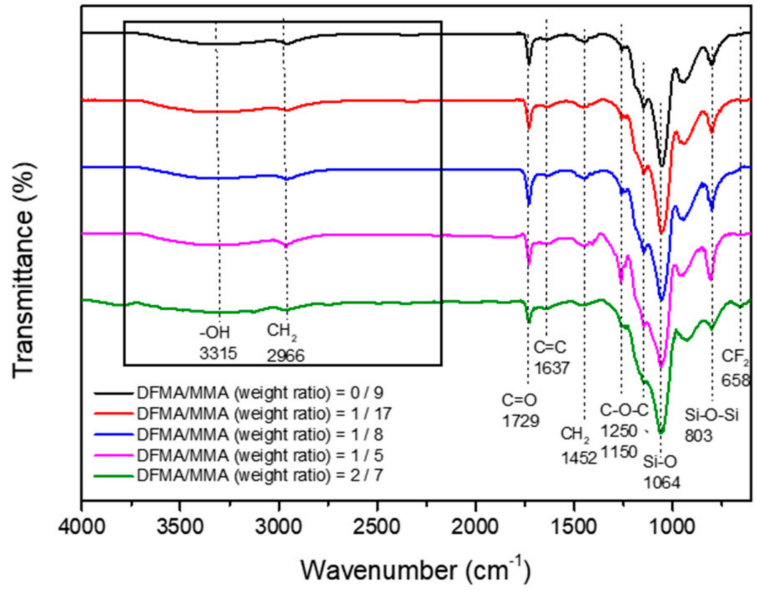

(b)

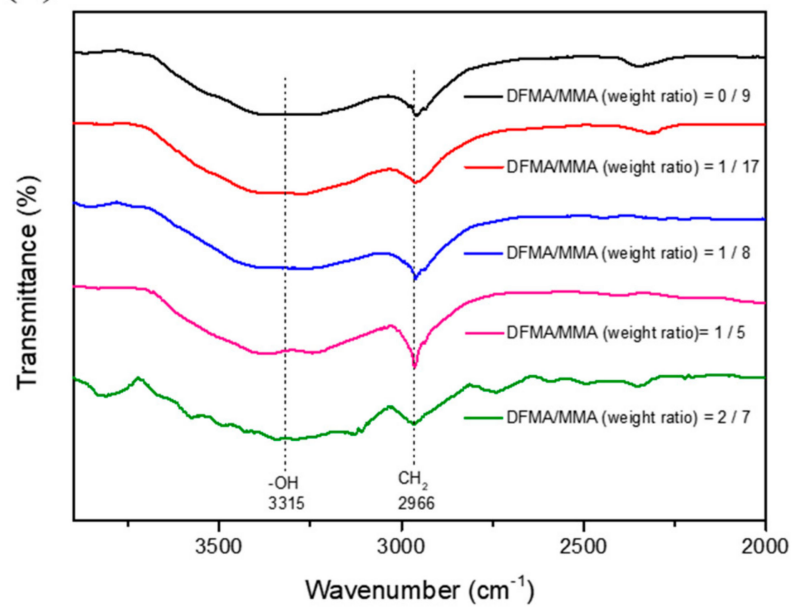

Figure 2. The Fourier transform infrared spectroscopy (FTIR) spectrum analysis of the prepared $\mathrm{SiO}_{2}$-polyacrylate material. (a) wavenumber range from $600 \mathrm{~cm}^{-1}$ to $4000 \mathrm{~cm}^{-1}$ and (b) a partial enlargement of (a).

Figure 3 shows the DSC analysis of the as-prepared nanohybrid silica polyacrylate materials prepared by different DFMA/MMA weight ratios. The results show that the glass transition temperature $\left(\mathrm{T}_{\mathrm{g}}\right)$ of the acrylate copolymer, obtained without adding the 
fluorine-containing monomer (weight ratio of DFMA/MMA at 0:9), is $72.8^{\circ} \mathrm{C}$. As the weight ratio of DFMA/MMA increases, the $\mathrm{T}_{\mathrm{g}}$ of the resulting copolymerized material shows a downward trend. When the weight ratio of DFMA/MMA is 1:5 (1.5:7.5), the $\mathrm{T}_{\mathrm{g}}$ of the obtained acrylate- $\mathrm{SiO}_{2}$ material drops to $56.0^{\circ} \mathrm{C}$. The $\mathrm{T}_{\mathrm{g}}$ of the homopolymer (PDFMA) polymerized from DFMA monomer is approximately $60{ }^{\circ} \mathrm{C}[54,55]$, which is lower than the $\mathrm{T}_{\mathrm{g}}\left(105^{\circ} \mathrm{C}\right)$ of PMMA obtained from the MMA monomer. Therefore, when the weight ratios of DFMA/MMA increase, the $\mathrm{T}_{\mathrm{g}}$ of the as-prepared polyacrylate- $\mathrm{SiO}_{2}$ materials decreases.

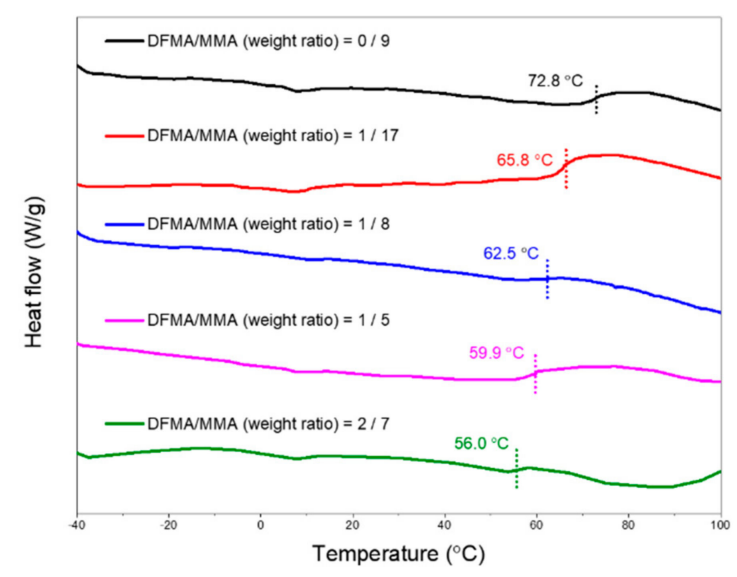

Figure 3. Differential scanning calorimetry (DSC) analysis of the as-prepared nanohybrid silica polyacrylate materials prepared by different dodecafluoroheptyl methacrylate (DFMA)/methyl methacrylate (MMA) weight ratios.

Figure 4 shows the TGA/DTA analyses of the as-prepared nanohybrid silica polyacrylate. It is observed that the thermal decomposition curves of the material by TGA (Figure 4a) can be divided into three stages. The first stage is $170-210{ }^{\circ} \mathrm{C}$ and exhibits a weight loss of about $5-10 \%$; this involves the unreacted monomers or impurities decomposed in the copolymer, resulting in thermogravimetric loss. The second stage is $230-310^{\circ} \mathrm{C}$ and exhibits a weight loss of approximately $30-40 \%$. The intermediate temperature peak is usually attributed to the cleavage of the double bond of the hydrocarbon group $\left(-\mathrm{CH}=\mathrm{CH}_{2}\right)$ in the acrylic copolymer. The third stage is $310-500{ }^{\circ} \mathrm{C}$, exhibiting a weight loss of about $45-55 \%$. This is the most important stage of the as-prepared $\mathrm{SiO}_{2}$-polyacrylate material during thermal pyrolysis. It is the random pyrolysis of the overall copolymer that causes the thermogravimetric loss. The TGA results are similar to the thermal decomposition of PMMA, as studied by Manring et al. [56].

However, it can be predicted from the TGA analysis from Figure 4 that the result of the decomposition starts at near the same temperature for all samples. Obviously, from the weight loss curve of TGA, the slopes of the curves are between approximately $200^{\circ} \mathrm{C}$ and $400{ }^{\circ} \mathrm{C}$ for the five samples. The result reveals that the samples prepared by weight ratios of DFMA/MMA of 2:7 and 1:5 have slightly lower slopes (the two are almost the same) than the other samples, which means that the fluorine-containing compound (DFMA) slightly increased the stability of the as-prepared polyacrylate at the same temperature in the temperature range of $200^{\circ} \mathrm{C}-400^{\circ} \mathrm{C}$. In particular, polyacrylate made from DFMA is more stable than that of material made without it, observed from the comparison of slope from weight loss curves.

Moreover, according to the DTA analysis (Figure 4b), the results show that, when the polyacrylate- $\mathrm{SiO}_{2}$ material is prepared without adding DFMA (weight ratio of DFMA/ MMA = 0:9), the fraction of low-temperature pyrolysis (the second stage: $230-310{ }^{\circ} \mathrm{C}$ ) is higher than those with added DFMA. On the contrary, when the weight ratios of DFMA/MMA increase, the fraction of low-temperature pyrolysis is much lower, while the fraction of high-temperature pyrolysis (third stage: $310-500^{\circ} \mathrm{C}$ ) increases. 
(a)

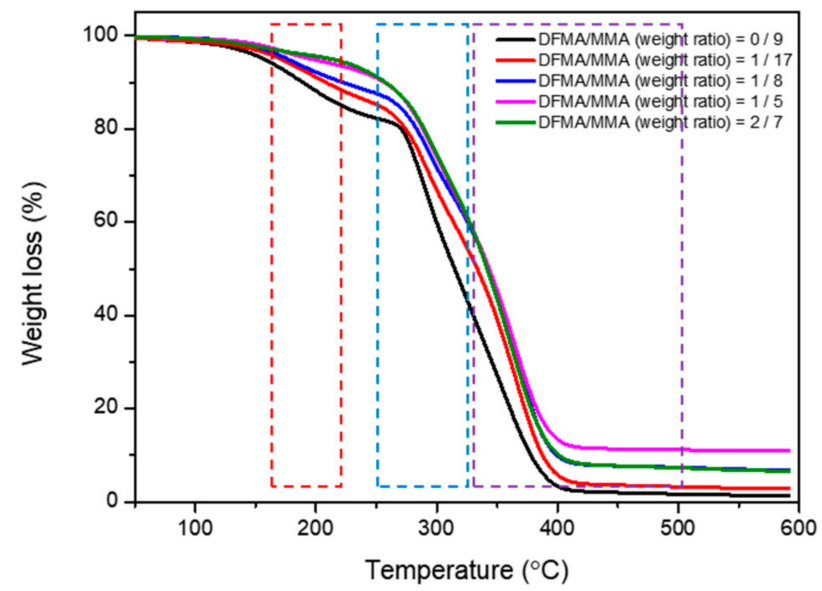

(b)

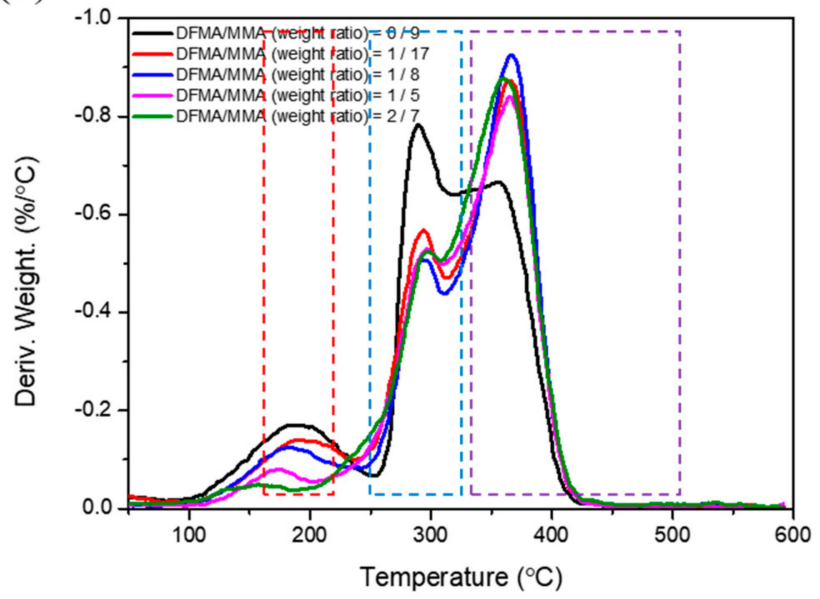

Figure 4. Thermogravimetric analyzer/differential thermal analyzer (TGA/DTA) analyses of the as-prepared nanohybrid silica polyacrylate. (a) TGA analysis and (b) DTA analysis.

\subsection{Morphology Analyses of the As-Prepared Nanohybrid Silica Polyacrylate Film}

Figure 5 shows the SEM analysis of the as-prepared nanohybrid silica polyacrylate film. As seen from Figure 5a, when the polyacrylate material was prepared without the addition of DFMA monomer, the surface of the coating film only presented flat round particles and the nanoparticle arrangement was very neat. As the weight ratio of DFMA/MMA increases, a few micro-protruding particles can be examined on the surface, as shown in Figure 5b-e. This may be owing to the strong hydrophobicity of the fluorine segment contained in the DFMA monomer, resulting in the $\mathrm{SiO}_{2}$ particles agglomerating and becoming larger during the formation of fluorine-containing polyacrylate- $\mathrm{SiO}_{2}$ hybrid material [55]. Figure 6 shows the mapping and EDS analysis of the nanohybrid silica polyacrylate film prepared by a weight ratio of DFMA/MMA at 1:5. It can be seen that $\mathrm{Si}$ and F elements are also uniformly dispersed in the coating film.

Figure 7 shows the TEM analysis of the as-prepared nanohybrid silica polyacrylate films. It can be seen from the figure that the black spherical nanoparticle is $\mathrm{SiO}_{2}$, prepared by grafting the Si-coupling agent with TEOS through the sol-gel route in the polyacrylate$\mathrm{SiO}_{2}$ hybrid material. The TEM image of the film was prepared without adding DFMA (Figure 7a) or a DFMA/MMA weight ratio of 1:5 (Figure 7b), respectively. It is clearly observed that, for the nanohybrid film obtained when the weight ratio of DFMA/MMA is 1:5, the particle size of the $\mathrm{SiO}_{2}$ in the hybrid material becomes larger, which is consistent with the results of Zhou et al. [57]. This may be because the greater hydrophilicity of Si sols renders them more open to becoming agglomerated during the sol-gel process, resulting in larger $\mathrm{SiO}_{2}$ particles, because the fluorine-containing segments in DFMA possesses strong hydrophobic properties [55]. This is in agreement with the aforementioned SEM analysis results.

Particularly, it is obvious from Figure $7 \mathrm{~b}$ that the self-assembled black $\mathrm{SiO}_{2}$ nanoparticle (core) is coated with a gray area on the periphery, which contains the grafting of KH-570 to $\mathrm{SiO}_{2}$ (shell) in the fluorine-containing nanohybrid silica polyacrylate material [56]. In addition, a large irregular gray area outside the core-shell structural sphere may be a fluorine-rich copolymer separated from the non-fluorine copolymer, caused by the poor compatibility of fluorine-containing and non-fluorine copolymers [52]. The TEM analysis indicates that the polyacrylate- $\mathrm{SiO}_{2}$ coating film has a self-assembled structure regardless of the presence of DFMA. It may be that the $\mathrm{Si}-\mathrm{OH}$ produced during the hydrolysis reaction of TEOS is a hydrophilic group, which is liable to self-assemble, with similar hydrophilic properties to the silicon coupling agent (KH-570), to form a core-shell structure in the nanohybrid silica polyacrylate material. 

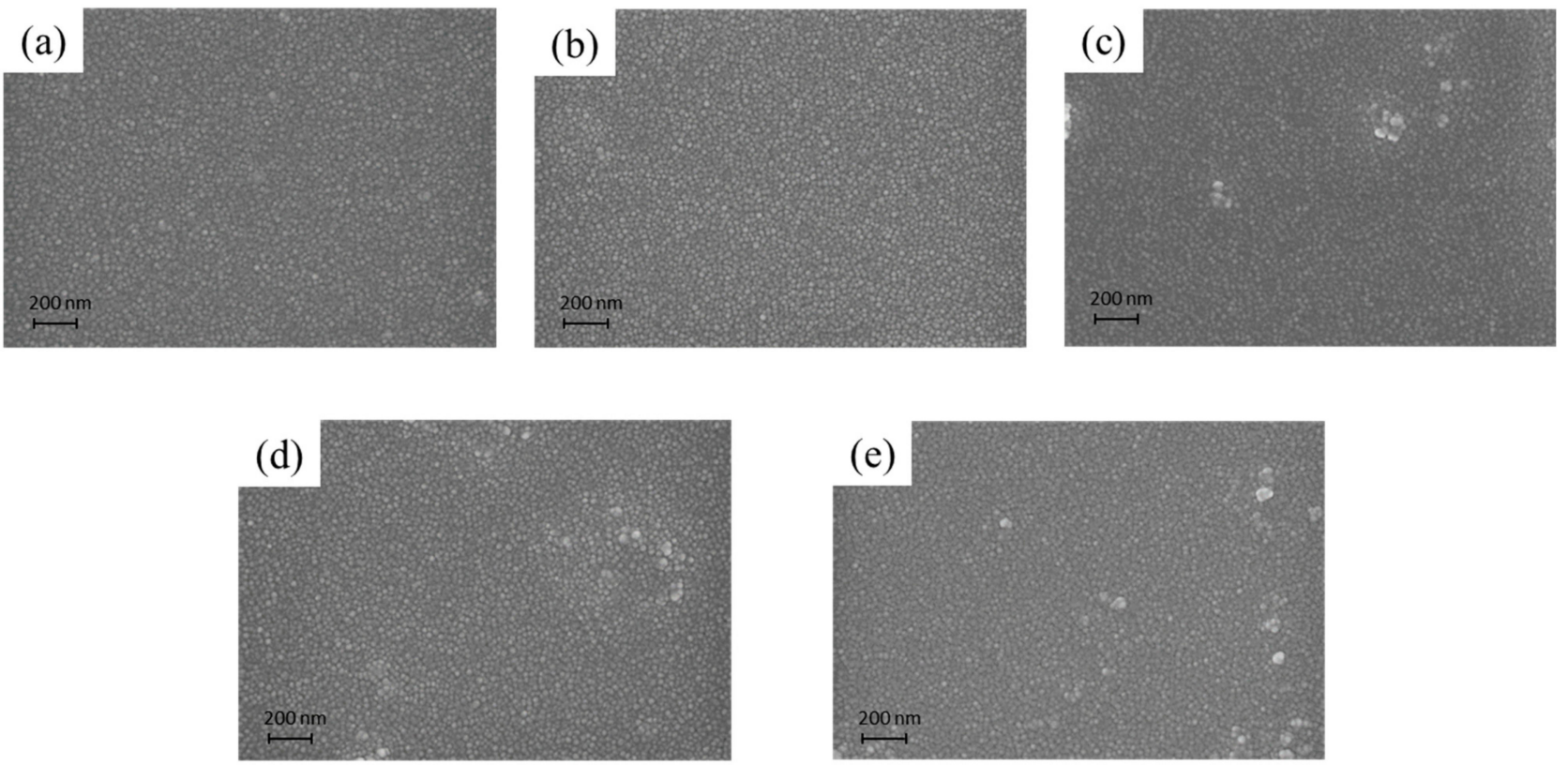

Figure 5. The scanning electron microscopy (SEM) analysis of the as-prepared nanohybrid silica polyacrylate film. (a) Without adding DFMA, (b) weight ratio of DFMA/MMA at 1:17, (c) weight ratio of DFMA/MMA at 1:8, (d) weight ratio of DFMA/MMA at 1:5, and (e) weight ratio of DFMA/MMA at 2:7.
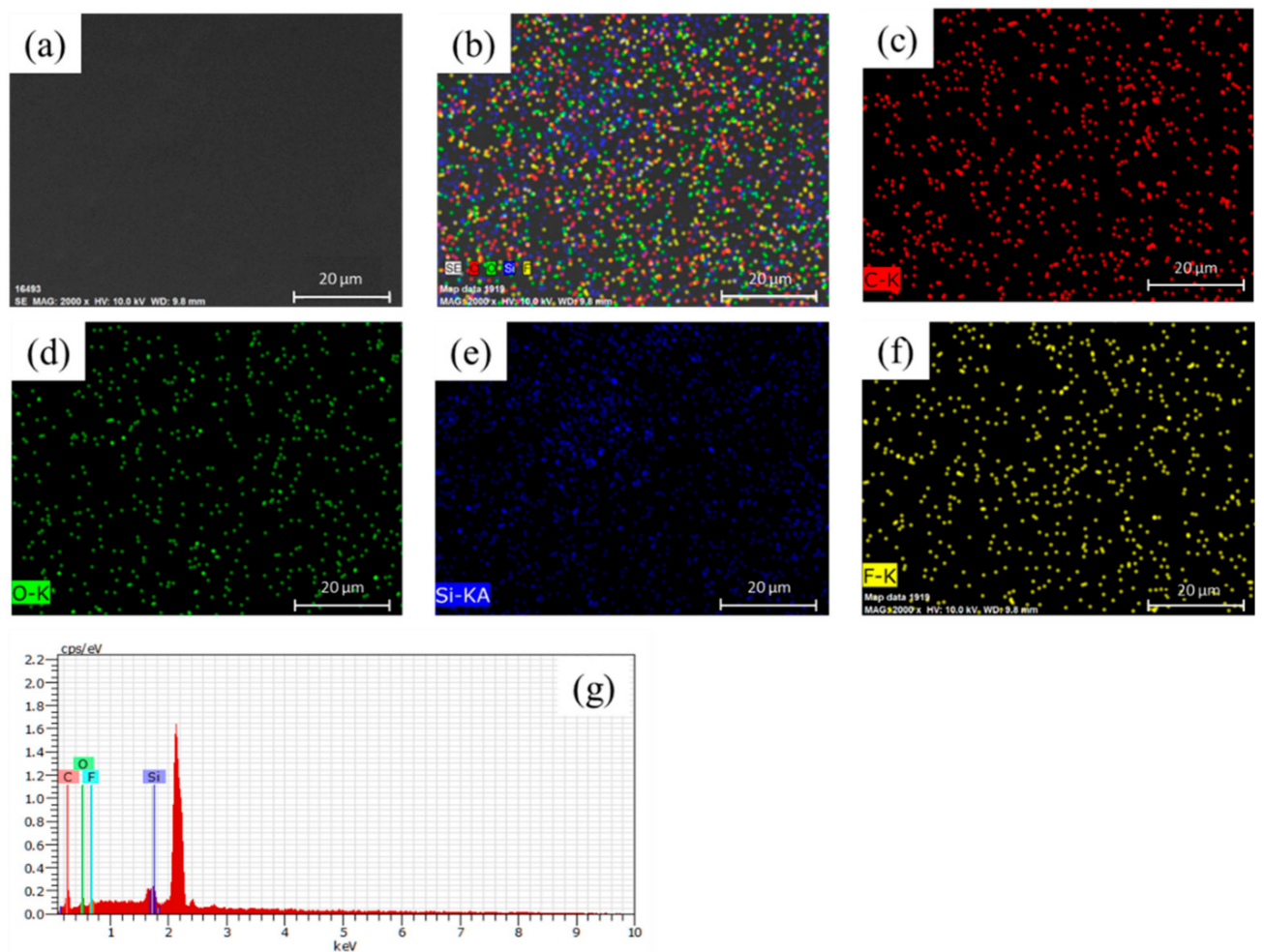

Figure 6. The mapping and EDS analysis nanohybrid silica polyacrylate film prepared by weight ratio of DFMA/MMA at 1:5. (a) SEM image of the as-prepared film, (b) mapping of C, O, Si, amd F elements on (a), (c) mapping of C element on (a), (d) mapping of O element on (a), (e) mapping of Si element on (a), (f) mapping of F element on (a), and (g) EDS analysis of the as-prepared film. 

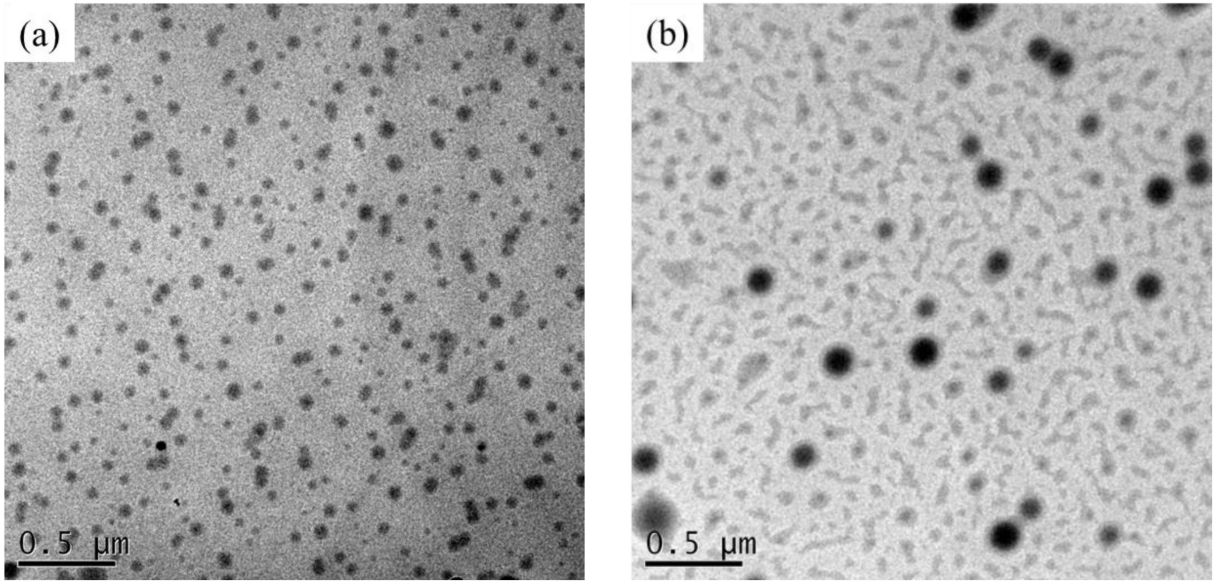

Figure 7. Transmission electronic microscopy (TEM) analysis of the as-prepared nanohybrid silica polyacrylate films. (a) Without adding DFMA and (b) DFMA/MMA weight ratio of 1:5.

Figure 8 shows the AFM image of the as-prepared nanohybrid silica polyacrylate films. The AFM image was taken in the scanning range of $1 \mu \mathrm{m} \times 1 \mu \mathrm{m}$. As the coating film was prepared without adding DFMA monomer, the root-mean-square (RMS) roughness of the coating film is $0.0566 \mathrm{~nm}$ (Figure $8 \mathrm{a}$ ). Figure $8 \mathrm{~b}$ shows the as-obtained film prepared with a DFMA/MMA weight ratio of 1:5; the RMS roughness of the surface of the nanohybrid silica polyacrylate film was $0.0638 \mathrm{~nm}$, which was $12 \%$ more than the film obtained without the addition of the DFMA monomer. It can be speculated that the fluorine-containing polyacrylate material migrates to the interface of the film and air. Because of the addition of the DFMA-containing fluorine segment group in the acrylate polymer, the micro-phase separation occurs when the film is cured, thus increasing the surface roughness of the coating film [58,59].
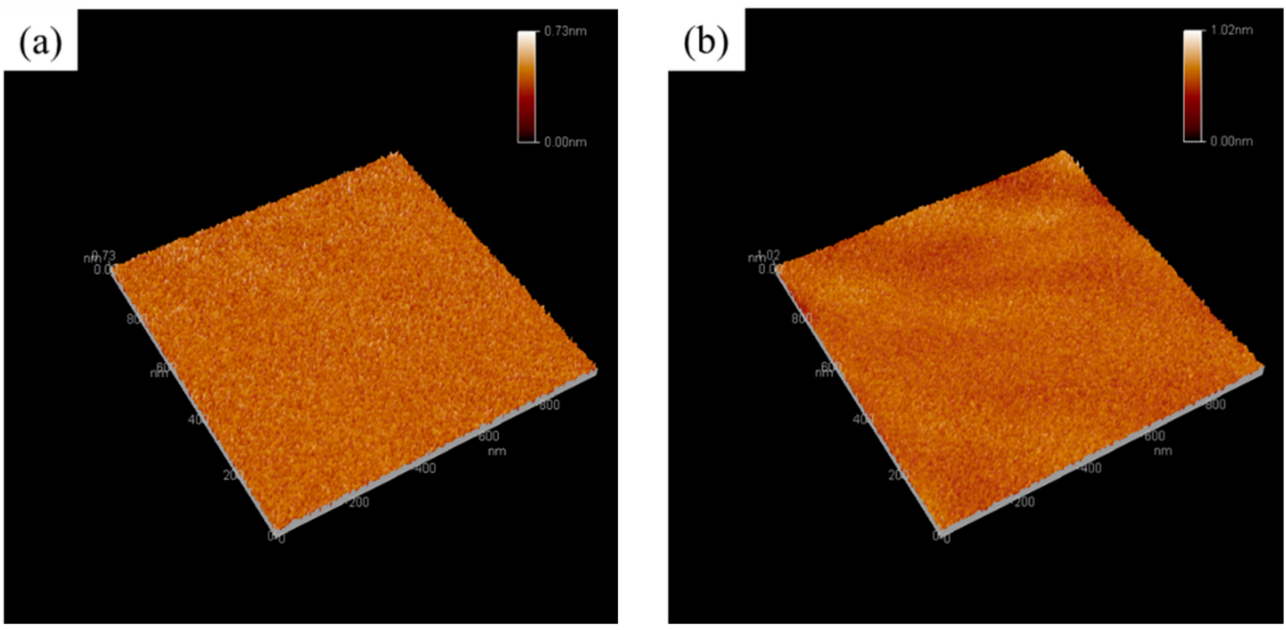

Figure 8. The atomic force microscopy (AFM) image of the as-prepared nanohybrid silica polyacrylate coating films. (a) Without adding DFMA and (b) DFMA/MMA weight ratio of 1:5.

\subsection{Hydrophobicity and Transparent Properties of Nanohybrid Silica Polyacrylate Film}

Figure 9 shows the water contact angle analysis of the as-prepared nanohybrid silica polyacrylate films prepared at different weight ratios of DFMA/MMA. Generally, when the water contact angle $(\theta)>90^{\circ}$, the surface is hydrophobic; when the water contact angle $(\theta)<90^{\circ}$, the surface is hydrophilic [2]. The figure shows that, when the weight ratio of DFMA/MMA changes from 0:9 to 1:5, the WCA of the as-prepared film increases from $93.0^{\circ}$ to $105.4^{\circ}$. This is because the fluorine-containing segment group has low surface energy [55], leading to an increase in surface roughness and an increase in hydrophobicity. 
This is consistent with the results of the AFM analysis. However, when the weight ratio of DFMA/MMA increases to 2:7 in the raw materials of nanohybrid silica polyacrylate, the water contact angle decreases to $97.5^{\circ}$ instead. As per the study of Zhou et al. [60], it has been proposed that, during the curing process of the higher fraction of fluorinecontaining acrylate, the excessive fluorine atoms increase the steric effect in the structure of the copolymer and hinder the migration of fluorine atoms to the surface of the coating film. In addition, fluorinated polyacrylate containing large mole fractions of DMFA is excluded as a result of coagulum formation during polymerization [60]. Zhou et al. [60] also reported a similar variation tendency in the water contact angle as a function of the dosage of fluorine-containing acrylate monomer, hexafluorobutyl acrylate (HFBA), used to prepare polyacrylate resin.

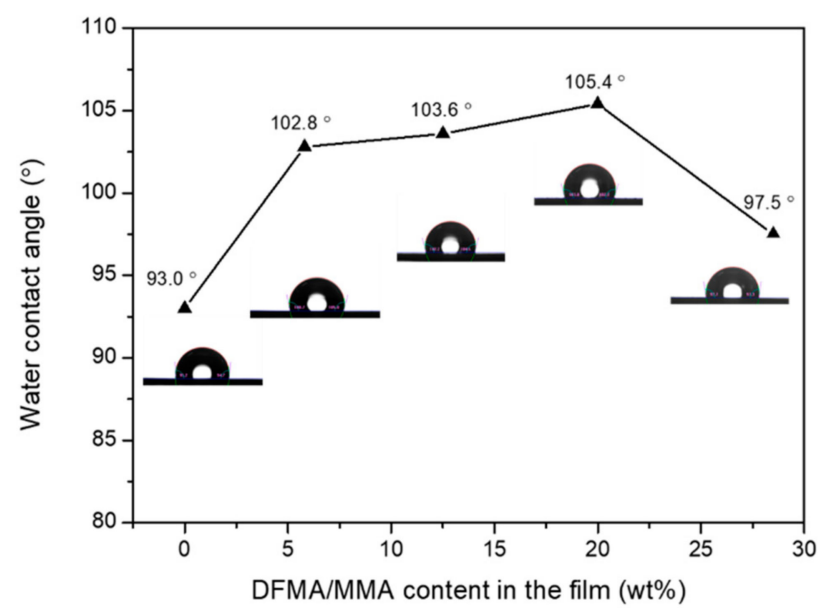

Figure 9. The water contact angle analysis of the as-prepared nanohybrid silica polyacrylate films prepared at different weight ratios of DFMA/MMA.

The transparency of the as-prepared nanohybrid silica polyacrylate film can be characterized by ultraviolet-visible (UV-vis) spectroscopy. Figure 10 shows the UV-vis analysis of the polyacrylate coating films prepared from different weight ratios of DFMA/MMA. At various weight ratios of DFMA/MMA, the transparency of the as-prepared acrylate film decreased slightly. This could be explained by the fact that, when the ratios of DFMA/MMA increase, the roughness will increase and the transparency will decrease [1]. However, the transmittance is maintained at $89-97 \%$ for all of the as-prepared coating films in the visible light region (with a wavelength of $380 \mathrm{~nm}-760 \mathrm{~nm}$ ). This result has a high transparency, with competitive capacity regarding the other hydrophobic coatings reported in the literature [61-63].

Combining the thermal stability, hydrophobic properties, and transparency of the asprepared fluorine-containing nanohybrid silica polyacrylate material, the hybrid material possesses superb performances. This indicates that the coating material could be a very attractive practical solution in many areas, such as in applications for the coatings of $3 \mathrm{C}$ electronic products, vehicles, and the construction industry, especially in outdoor applications. 


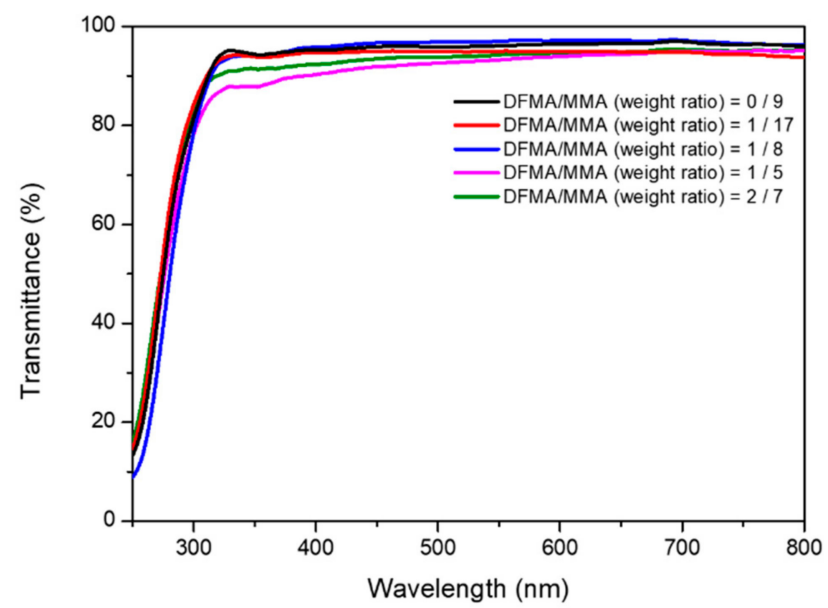

Figure 10. The UV-vis analysis of the polyacrylate coating films prepared from different weight ratios of DFMA/MMA.

\section{Conclusions}

In this study, a fluorine-containing nanohybrid silica polyacrylate coating material was synthesized successfully by free radical polymerization and grafting with an organic-silicon compound. The influences of the DFMA/MMA weight ratios on the hydrophobic and transparent properties of the as-prepared coating film were discussed. The results indicated that the fluorine-containing group from DFMA improved the hydrophobic performance of the as-prepared polyacrylate- $\mathrm{SiO}_{2}$ nanohybrid film. The surface morphology of the as-prepared coating film exhibited spherical shape silica nanoparticle hybridizing with polyacrylic-based copolymer by grafting the coupling agent. The greater $\mathrm{SiO}_{2}$ particles exhibit an increase in surface roughness and enhance the hydrophobic properties of the as-obtained coating film, because the fluorine-containing segments in DFMA possess strong hydrophobic properties. Furthermore, the particle size of $\mathrm{SiO}_{2}$ in the material is larger when the weight ratio of DFMA/MMA is higher, because of the strong hydrophobic properties. The hydrophobic properties of the as-prepared coating film increase with the increase in the weight ratio of DFMA/MMA and reach their maximum values at 1:5. Furthermore, the increase in the weight ratio of DFMA/MMA lowers the hydrophobic performance. In addition, the thermal stability of the as-prepared nanohybrid silica polyacrylate material can be enhanced by the content of DFMA monomer that is added. Moreover, the surface morphology of the silicon coupling agent used to graft $\mathrm{SiO}_{2}$ with acrylate is spherical in shape and exhibits a core-shell structure, which increases the surface roughness and improves the hydrophobicity of the nanohybrid film. The as-prepared fluorine-containing nanohybrid silica polyacrylate film demonstrates a high transmittance of $89-97 \%$ in the visible light region.

Author Contributions: W.-D.Y. conceived and designed the experiments; S.-Y.F. performed the experiments; H.-Y.W. analyzed the data; C.-M.H. wrote the paper. All authors have read and agreed to the published version of the manuscript.

Funding: The authors wish to thank the Ministry of Science and Technology of Taiwan for its financial support under grant No. MOST-109-2637-E-992-001.

Institutional Review Board Statement: Not applicable.

Informed Consent Statement: Not applicable.

Data Availability Statement: Data sharing is not applicable for this article.

Conflicts of Interest: The authors declare no conflict of interest. 


\section{References}

1. Liu, K.; Jiang, L. Bio-inspired design of multiscale structures for function integration. Nano Today 2011, 6, 155-175. [CrossRef]

2. Zhang, B.; Liu, B.; Deng, X.; Cao, S.; Hou, X.; Chen, H. A novel approach for the preparation of organic-siloxane oligomers and the creation of hydrophobic surface. Appl. Surf. Sci. 2007, 254, 452-458. [CrossRef]

3. Bhushan, B.; Jung, Y.C. Natural and biomimetic artificial surfaces for superhydrophobicity, self-cleaning, low adhesion, and drag reduction. Prog. Mater. Sci. 2011, 56, 1-108. [CrossRef]

4. Liu, C.J.; Feng, X.Y.; Li, N.; Luo, C.W.; Chao, Z.S. Super-hydrophobic $\mathrm{Co}_{3} \mathrm{O}_{4}$-loaded nickel foam with corrosion-resistant property prepared by combination of hydrothermal synthesis and PFAS modification. Surf. Coat. Technol. 2017, 309, 1111-1118. [CrossRef]

5. Ebert, D.; Bhushan, B. Transparent, superhydrophobic, and wear-resistant surfaces using deep reactive ion etching on PDMS substrates. J. Colloid Interface Sci. 2016, 481, 82-90. [CrossRef]

6. Pintossia, D.; Colombob, A.; Levia, M.; Dragonettib, C.; Turria, S.; Griffinia, G. UV-curable fluoropolymers crosslinked with functional fluorescent dyes: The way to multifunctional thin-film luminescent solar concentrators. J. Mater. Chem. A 2017, 5, 1-11. [CrossRef]

7. Choi, D.; Yoo, J.; Park, S.M.; Kim, D.S. Facile and cost-effective fabrication of patternable superhydrophobic surfaces via salt dissolution assisted etching. Appl. Surf. Sci. 2017, 393, 449-456. [CrossRef]

8. Kim, D.; Park, S.-J.; Jeon, S.B.; Seol, M.L.; Choi, Y.K. A triboelectric sponge fabricated from a cube sugar template by 3D soft lithography for superhydrophobicity and elasticity. Adv. Electron. Mater. 2016, 2, 1500331. [CrossRef]

9. Kothary, P.; Dou, X.; Fang, Y.; Gu, Z.; Leo, S.Y.; Jiang, P. Superhydrophobic hierarchical arrays fabricated by a scalable colloidal lithography approach. J. Colloid Interface Sci. 2017, 487, 484-492. [CrossRef]

10. Siddiqui, A.R.; Maurya, R.; Balani, K. Superhydrophobic self-floating carbon nanofiber coating for efficient gravity-directed oil/water separation. J. Mater. Chem. A 2017, 5, 2936-2946. [CrossRef]

11. Zhou, S.; Zhu, X.; Yan, Q. One-step electrochemical deposition to achieve superhydrophobic cobalt incorporated amorphous carbon-based film with self-cleaning and anti-corrosion. Surf. Interface Anal. 2017, 50, 1-7. [CrossRef]

12. Yin, Y.; Huang, R.; Zhang, W.; Zhang, M.; Wang, C. Superhydrophobic-superhydrophilic switchable wettability via TiO 2 photoinduction electrochemical deposition on cellulose substrate. Chem. Eng. J. 2016, 289, 99-105. [CrossRef]

13. Li, S.Y.; Xiang, X.G.; Ma, B.H.; Meng, X.D. Facile preparation of diverse alumina surface structures by anodization and superhydrophobic surfaces with tunable water droplet adhesion. J. Alloys Compd. 2019, 779, 219-228. [CrossRef]

14. Vengatesh, P.; Kulandainathan, M.A. Hierarchically ordered self-lubricating superhydrophobic anodized aluminum surfaces with enhanced corrosion resistance. ACS Appl. Mater. Interfaces 2015, 7, 1516-1526. [CrossRef] [PubMed]

15. Xu, P.; Pershin, L.; Mostaghimi, J.; Coyle, T.W. Efficient one-step fabrication of ceramic superhydrophobic coatings by solution precursor plasma spray. Mater. Lett. 2018, 211, 24-27. [CrossRef]

16. Dimitrakellis, P.; Gogolides, E. Hydrophobic and superhydrophobic surfaces fabricated using atmospheric pressure cold plasma technology: A review. Adv. Colloid Interface Sci. 2018, 254, 1-21. [CrossRef]

17. Ryu, J.; Kim, K.; Park, J.Y.; Hwang, B.G.; Ko, Y.C.; Kim, H.J.; Han, J.S.; Seo, E.R.; Park, Y.J.; Lee, S.J. Nearly perfect durable superhydrophobic surfaces fabricated by a simple one-step plasma treatment. Sci. Rep. 2017, 7, 1981. [CrossRef]

18. Fleming, R.A.; Zou, M. Silica nanoparticle-based films on titanium substrates with long-term superhydrophilic and superhydrophobic stability. Appl. Surf. Sci. 2013, 280, 820-827. [CrossRef]

19. Gao, J.; Huang, X.; Wang, L.; Zheng, N.; Li, W.; Xue, H.; Li, R.K.Y.; Mai, Y.W. Super-hydrophobic coatings based on non-solvent induced phase separation during electro-spraying. J. Colloid Interface Sci. 2017, 506, 603-612. [CrossRef]

20. Latthe, S.S.; Terashima, C.; Nakata, K.; Sakaib, M.; Fujishima, A. Development of sol-gel processed semi-transparent and self-cleaning superhydrophobic coatings. J. Mater. Chem. A 2014, 2, 5548-5553. [CrossRef]

21. Gurav, A.B.; Latthe, S.S.; Vhatkar, R.S. Sol-gel-processed porous water-repellent silica microbowls. Surf. Innov. $2013,1,157-161$. [CrossRef]

22. Guo, X.J.; Xue, C.H.; Li, M.; Lic, X.; Ma, J.Z. Fabrication of robust, superhydrophobic, electrically conductive and UV-blocking fabrics via layer-by-layer assembly of carbon nanotubes. RSC Adv. 2017, 7, 25560-25565. [CrossRef]

23. Peng, L.; Meng, Y.; Li, H. Facile fabrication of superhydrophobic paper with improved physical strength by a novel layer-by-layer assembly of polyelectrolytes and lignosulfonates-amine. Cellulose 2016, 23, 2073-2085. [CrossRef]

24. Chau, J.L.H.; Hsieh, C.C.; Lin, Y.M.; Li, A.K. Preparation of transparent silica-PMMA nanocomposite hard coatings. Prog. Org. Coat. 2008, 62, 436-439. [CrossRef]

25. Motamedi, M.; Ramezanzadeh, M.; Ramezanzadeh, B.; Mahdavian, M. One-pot synthesis and construction of a high performance metal-organic structured nano pigment based on nanoceria decorated cerium (III)-17 imidazole network (NC/CIN) for effective epoxy composite coating anti-corrosion and thermomechanical properties improvement. Chem. Eng. J. 2020, 382, 122820. [CrossRef]

26. Yu, S.; Zhou, Y.; Zhang, T.; He, M. Preparation and characterization of acrylate copolymers modified by fluorine and silicon for application in release films. Polym. Plast. Technol. 2014, 53, 531-538. [CrossRef]

27. Zhi, D.F.; Lu, Y.; Sathasivam, S.; Parkin, I.P.; Zhang, X. Large-scale fabrication of translucent and repairable superhydrophobic spray coatings with remarkable mechanical, chemical durability and UV resistance. J. Mater. Chem. A 2017, 5, 10622-10631. [CrossRef] 
28. Huang, K.; Liu, Y.; Wu, D. Synthesis and characterization of polyacrylate modified by polysiloxane latexes and films. Prog. Org. Coat. 2014, 77, 1774-1779. [CrossRef]

29. Liu, X.; Cui, X.; Zhang, C.; Zhang, X.; Wu, G. Effects of different silanization followed via the sol-gel growing of silica nanoparticles onto carbon fiber on interfacial strength of silicone resin composites. Chem. Phys. Lett. 2018, 707, 1-7. [CrossRef]

30. Yeh, J.-M.; Weng, C.-J.; Liao, W.-J.; Mau, Y.-W. Anticorrosively enhanced PMMA-SiO 2 hybrid coatings prepared from the sol-gel approach with MSMA as the coupling agent. Surf. Coat. Technol. 2006, 201, 1788-1795. [CrossRef]

31. Arai, K.; Mizutani, T.; Miyamoto, M.; Kimura, Y.; Aoki, T. Colloidal silica bearing thin polyacrylate coat: A facile inorganic modifier of acrylic emulsions for fabricating hybrid films with least aggregation of silica nanoparticles. Prog. Org. Coat. 2019, 128, 11-20. [CrossRef]

32. Kozakiewicz, J.; Trzaskowska, J.; Domanowski, W.; Kieplin, A.; Ofat-Kawalec, I.; Przybylski, J.; Woźniak, M.; Witwicki, D.; Sylwestrzak, K. Studies on synthesis and characterization of aqueous hybrid silicone-acrylic and acrylic-silicone dispersions and coatings: Part II. Prog. Org. Coat. 2020, 138, 105297. [CrossRef]

33. Xiao, Z.; Guo, P.; Sun, N. Preparation, thermostability, and hydrophobic properties of $\mathrm{TiO}_{2} /$ poly(dodecafluoroheptyl methacrylate) nanocomposites. J. Appl. Polym. Sci. 2016, 134, 44377. [CrossRef]

34. Li, M.; Li, Y.; Xue, F.; Jing, X. Water-based acrylate copolymer/silica hybrids for facile preparation of robust and durable superhydrophobic coatings. Appl. Surf. Sci. 2018, 447, 489-499. [CrossRef]

35. Xu, W.; Wang, S.; Hao, L.; Wang, X. Preparation and characterization of trilayer core-shell polysilsesquioxane-fluoroacrylate copolymer composite emulsion particles. J. Appl. Polym. Sci. 2017, 134, 44845. [CrossRef]

36. Fang, Y.; Wang, D.; Jing, X.; Xue, B. Synthesis and characterization of fluorinated organic-inorganic hybrid coatings on tinplate. J. Appl. Polym. Sci. 2015, 132, 42428. [CrossRef]

37. Chen, Y.; Kim, H. Poly(vinylidene fluoride) grafted with 3-trimethoxysilylpropyl methacrylate for silyl functional membranes. React. Funct. Polym. 2008, 68, 1499-1506. [CrossRef]

38. Tung, Y.C.; Chen, W.C. Poly[2,7-(9,9-dihexylfluorene)-block-poly[3-(trimethoxysilyl)propyl methacrylate (PF-b-PTMSPMA) rod-coil block copolymers: Synthesis, morphology and photophysical properties in mixed solvents. React. Funct. Polym. 2009, 69, 507-518. [CrossRef]

39. Liu, Y.; Wang, M.; Li, Z.; Liu, H.; He, P.; Li, J. Preparation of porous aminopropylsilsesquioxane by a nonhydrolytic sol-gel method in ionic liquid solvent. Langmuir 2005, 21, 1618-1622. [CrossRef] [PubMed]

40. Wu, Y.L.; She, W.; Shi, D.; Jiang, T.; Hao, T.H.; Liu, J.; Zhang, Q.C.; You, J.; Li, R.Y. An extremely chemical and mechanically durable siloxane bearing copolymer coating with self-crosslinkable and anti-icing properties. Compos. Part B 2020, $195,108031$. [CrossRef]

41. Yu, S.; Guo, Z.; Liu, W. Biomimetic Transparent and Superhydrophobic Coatings: From Nature and beyond Nature. Chem. Commun. 2015, 51, 1775-1794. [CrossRef]

42. Zhu, B.; Liu, Z.; Liu, J.; Yang, Y.; Meng, Y.; Yu, F.; Jiang, L.; Wei, G.; Zhang, Z. Preparation of fluorinated/silanized polyacrylates amphiphilic polymers and their anticorrosion and antifouling performance. Prog. Org. Coat. 2020, 140, 105510. [CrossRef]

43. Yu, F.; Gao, J.; Liu, C.; Chen, Y.; Zhong, G.; Hodges, C.; Chen, M.; Zhang, H. Preparation and UV aging of nano-SiO $2 /$ fluorinated polyacrylate polyurethane hydrophobic composite coating. Prog. Org. Coat. 2020, 141, 105556. [CrossRef]

44. Li, H.; Zhou, J.; Zhao, J.; Li, Y.; Lu, K. Synthesis of cellulose nanocrystals-armored fluorinated polyacrylate latexes via Pickering emulsion polymerization and their film properties. Colloids Surf. B 2020, 192, 111071. [CrossRef]

45. Wang, X.; Cui, Y.; Wang, Y.; Ban, T.; Zhang, Y.; Zhang, J.; Zhu, X. Preparation and characteristics of crosslinked fluorinated acrylate modified waterborne polyurethane for metal protection coating. Prog. Org. Coat. 2021, 158, 106371. [CrossRef]

46. Lyu, B.; Li, X.; Liu, H.; Gao, D.; Ma, J.; Zhang, M. Preparation of an amphiphilic Janus $\mathrm{SiO}_{2}$ /fluorinated polyacrylate latex film and its application as a hydrophobic fabric agent. J. Colloid Interface Sci. 2021, 599, 88-99. [CrossRef]

47. Shao, T.; Chen, X.; Chen, L. Preparation and characterization of self-cross-linking long fluorocarbon polyacrylate latex modified by silane cross-linker. Pigment Resin Technol. 2020. [CrossRef]

48. Nagarale, R.K.; Shin, W.; Singh, P.K. Progress in ionic organic-inorganic composite membranes for fuel cell applications. Polym. Chem. 2010, 1, 388-408. [CrossRef]

49. Xu, S.; Liu, W. Synthesis and surface characterization of an amphiphilic fluorinated copolymer via emulsifier-free emulsion polymerization of RAFT. J. Fluor. Chem. 2008, 129, 125-130. [CrossRef]

50. Fang, C.; Huang, X.; Ge, T.; Li, Y.; Cao, Y.; Zhu, X.; Dong, X. Effect of dodecafluoroheptyl methacrylate (DFMA) on the comprehensive properties of acrylate emulsion pressure sensitive adhesives. Int. J. Adhes. Adhes. 2020, 101, 102634. [CrossRef]

51. Ni, H.; Wang, X.; Zhang, W.; Wang, X.; Shen, Z. Stable hydrophobic surfaces created by self-assembly of poly (methyl methacrylate) end-capped with 2-perfluorooctylethyl methacrylate units. Surf. Sci. 2007, 601, 3632-3639. [CrossRef]

52. Lü, T.; Qi, D.; Zhang, D.; Liu, Q.; Zhao, H. Fabrication of self-cross-linking fluorinated polyacrylate latex particles with core-shell structure and film properties. React. Funct. Polym. 2016, 104, 9-14. [CrossRef]

53. Wang, Y.; Long, J.; Bai, Y.; Zhang, C.; Cheng, B.; Shao, L.; Qi, S. Preparation and characterization of fluorinated acrylic pressure sensitive adhesives for low surface energy substrates. J. Fluorine Chem. 2015, 180, 103-109. [CrossRef]

54. Xu, W.; An, Q.; Hao, L.; Zhang, D.; Zhang, M. Synthesis and characterization of self-crosslinking fluorinated polyacrylate soap-free latices with core-shell structure. Appl. Surf. Sci. 2013, 268, 373-380. [CrossRef] 
55. Zhang, Q.; Zhan, X.; Chen, F.; Shi, Y.; Wang, Q. Block copolymers of dodecafluoroheptyl methacrylate and butyl methacrylate by RAFT miniemulsion polymerization. J. Polym. Sci. Part A Polym. Chem. 2007, 45, 1585-1594. [CrossRef]

56. Manring, L.E. Thermal degradation of poly(methyl methacrylate). 2. Vinyl-terminated polymer. Macromolecules 1989, 22, 2673-2677. [CrossRef]

57. Zhou, J.; Ghen, X.; Duan, H.; Ma, J. Synthesis and characterization of organic fluorine and nano-SiO 2 modified polyacrylate emulsifier-free latex. Prog. Org. Coat. 2015, 89, 192-198. [CrossRef]

58. Yang, X.; Zhu, L.; Zhang, Y.; Chen, Y.; Bao, B.; Xu, J.; Zhou, W. Surface properties and self-cleaning ability of the fluorinated acrylate coatings modified with dodecafluoroheptyl methacrylate through two adding ways. Appl. Surf. Sci. 2014, $295,44-49$. [CrossRef]

59. Zhou, J.; Chen, X.; Duan, H.; Ma, J.; Ma, Y. Synthesis and Characterization of nano-SiO 2 modified fluorine-containing polyacrylate emulsifier-free emulsion. Appl. Surf. Sci. 2015, 331, 504-511. [CrossRef]

60. Zhou, J.; Zhang, L.; Ma, J. Fluorinated polyacrylate emulsifier-free emulsion mediated by poly(acrylic acid)-b-poly(hexafluorobutyl acrylate) trithiocarbonate via ab initio RAFT emulsion polymerization. Chem. Eng. J. 2013, 223, 8-17. [CrossRef]

61. Siddiqui, A.R.; Li, W.; Wang, F.; Ou, J.; Amirfazli, A. One-step fabrication of transparent superhydrophobic surface. Appl. Surf. Sci. 2021, 542, 148534. [CrossRef]

62. Zhang, C.; Kalulu, M.; Sun, S.; Jiang, P.; Zhou, X.; Wei, Y.; Jiang, Y. Environmentally safe, durable and transparent superhydrophobic coating prepared by one-step spraying. Colloids Surf. A 2019, 570, 147-155. [CrossRef]

63. Ji, Z.; Liu, Y.; Du, F. Rational design of superhydrophobic, transparent hybrid coating with superior durability. Prog. Org. Coat. 2021, 157, 106294. [CrossRef] 